\title{
Coherent rainfall zones: Case study for Karnataka
}

\author{
SULOCHANA GADGIL, R GOWRI and YADUMANI \\ Centre for Atmospheric Sciences, Indian Institute of Science, Bangalorc 560012, India
}

MS received 3 February 1988; revised 28 July 1988

\begin{abstract}
Generally average rainfall over meteorological subdivisions is used for assessment of the variability of monsoon rainfall. It is shown here that variations of seasonal rainfall over the meteorological subdivisions of interior Karnataka are not coherent. A methodology for delineating coherent rainfall zones is developed in this paper and applied to derive such zones for the State of Karnataka.
\end{abstract}

Keywords. Monsoon variability; coherent rainfall zones.

\section{Introduction}

The major problem in monsoon meteorology is understanding the nature of the variability of the monsoon rainfall on different spatial and temporal scales. Over the monsoonal regions there is a large interannual variability of rainfall from droughts to years with a good monsoon. The severity of droughts can be assessed either in terms of the deficit of the rainfall in a season/year or in terms of the impact on critical resources such as agriculture. Generally droughts are defined in terms of the deficit of rainfall because it is not easy to assess quantitatively the impact on specific resources, Large anomalies in seasonal or annual rainfall generally occur simultaneously over regions which are hundreds of kilometers in extent because the monsoon is a planetary scale phenomenon. Hence the average rainfall over regions of this spatial scale viz the meteorological subdivisions (figure 1), is used by the India Meteorological Department for assessment of the monsoon performance in a specific year or a season.

It is clear that such an assessment is meaningful only if the variations of the rainfall for the period of interest are coherent over each of the meteorological subdivisions. Otherwise, even when the subdivisional average rainfall is normal, parts of the subdivision may experience drought while the rainfall may be normal or in excess over the rest. Our analysis of the time series of monthly rainfall over the State of Karnataka (figure 1) has revealed that two of the three meteorological subdivisions of the State are not coherent with respect to the variation of annual and seasonal rainfall. This implies that the subdivisional average does not reflect the experience of the subregions within these subdivisions and the availability of critical resources such as agricultural produce and water may not be related to the quantity of the subdivisional rainfall. For a meaningful assessment of the variability of rainfall it is necessary to use zones over which rainfall variations are coherent over the time scale of interest. Such coherent rainfall zones have to be identified for defining the occurrence of droughts, estimating their impact and for planning remedial measures. Clearly, coherent zones should form the basic unit for deriving the detailed statistics of rainfall variation during the 


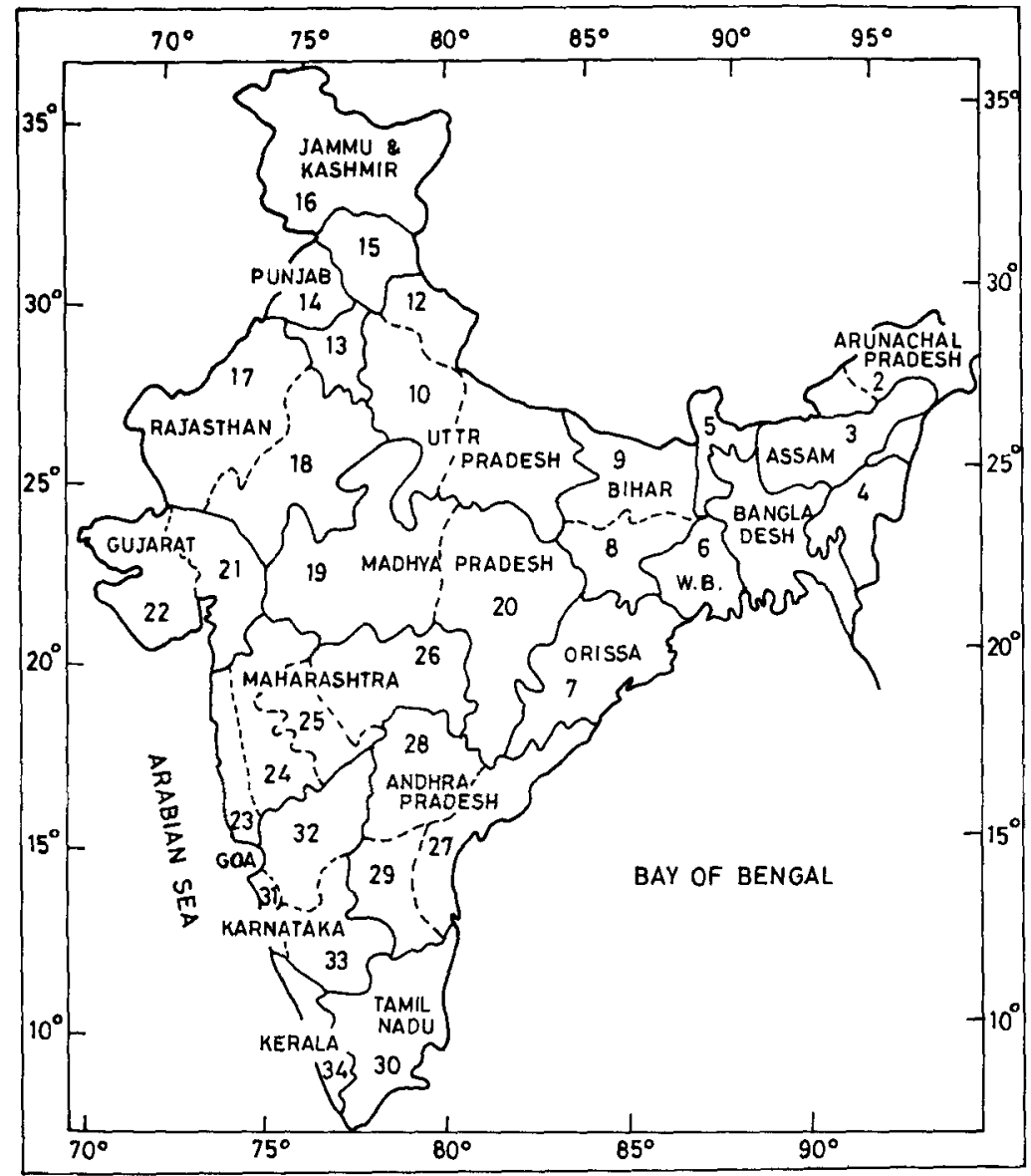

Figure 1. Meteorological subdivisions of India (after Rao 1976).

timescale chosen (such as the dependable rainfall at different probability levels) which is necessary for proper planning of the utilization of water resources and for determining the optimal agricultural strategy.

In this paper we illustrate the methodology we have developed for identification of coherent rainfall zones by delineating these zones for the State of Karnataka. In $\S 2$ the basic data and the nature of the variation of rainfall over the study region are described. The measures of coherence used and the methodology developed for identification of coherent regions are discussed in $\$ \S 3$ and 4 respectively. The delineation of the coherent zones of the State of Karnataka is discussed in $\S 5$. The extent to which the zones thus derived are coherent with respect to the occurrence of large anomalies in seasonal and annual rainfall is estimated in $\$ 6$ and the implications of the different definitions of meteorological droughts are discussed in $\$ 7$.

\section{Rainfall in Karnataka: basic features}

The data analysed comprise monthly rainfall during 1901-1985 at 50 well-distributed stations in the State of Karnataka. The meteorological subdivisions of the State and the 


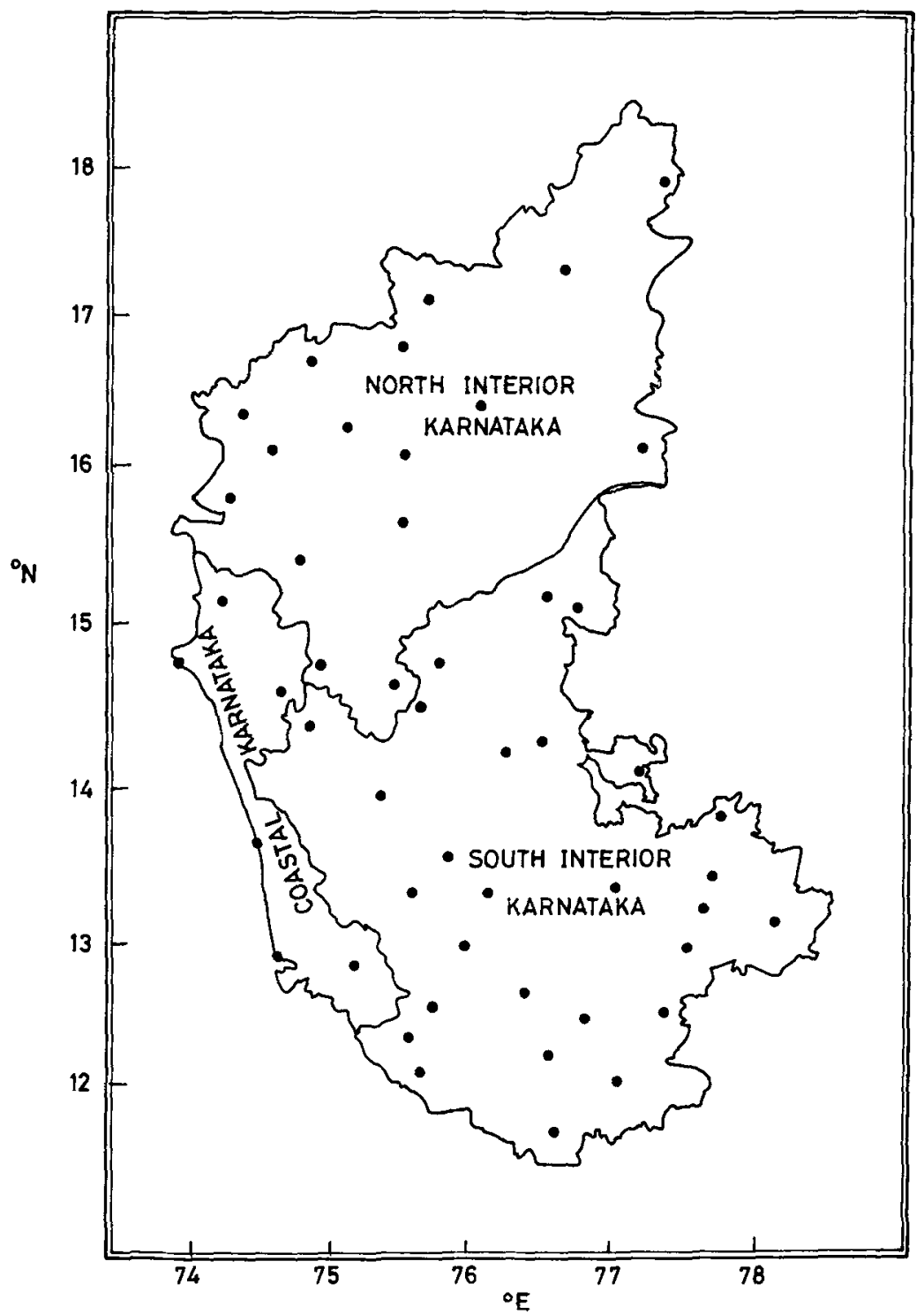

Figure 2. Meteorological subdivisions of Karnataka and the network of stations used.

network of stations used are shown in figure 2. There is considerable variation in the average annual rainfall as well as the average rainfall pattern i.e. the distribution of rainfall within the year, across the State (figure 3). Most of the rainfall occurs during two seasons viz the summer monsoon (June-September) and the post-monsoon (October-December). In addition, some rainfall is also received during the premonsoon season i.e. March-May. Our aim is to delineate zones of the State which are coherent with respect to the variations in the annual rainfall and rainfall in the two major rainy seasons. In fact the zones so determined also turn out to be coherent for variation of rainfall in each of the major rainy months. 


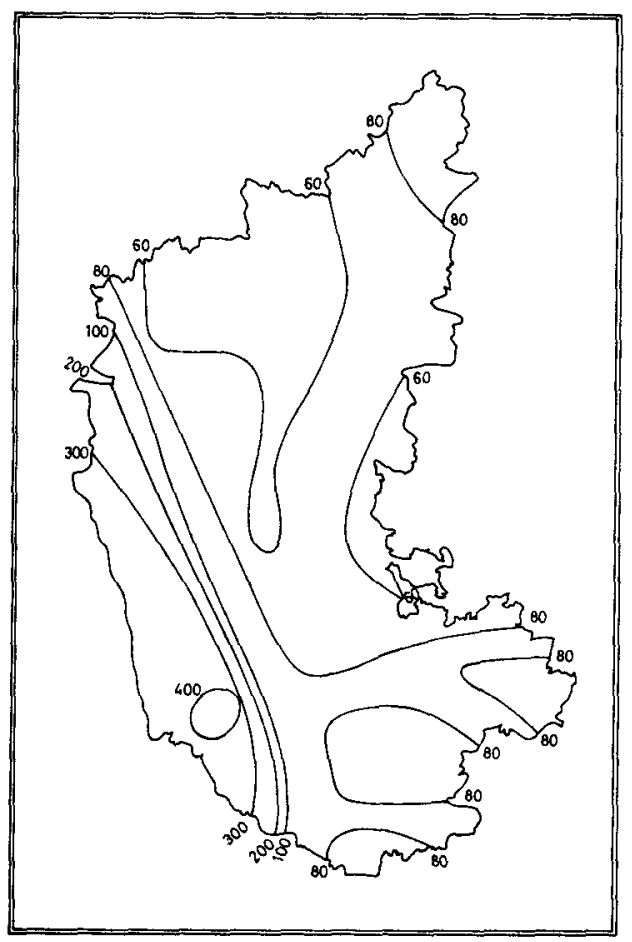

(a)

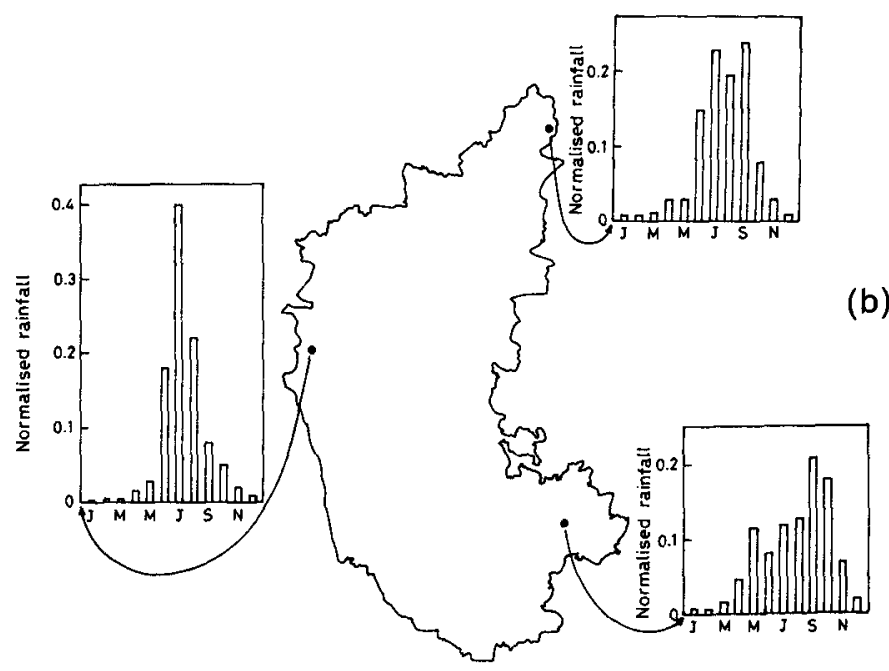

Figure 3. (a) Mean annual rainfall at different stations. (b) Mean monthly rainfall at three different stations: Supa $\left(15 \cdot 16^{\circ} \mathrm{N}, 74 \cdot 3^{\circ} \mathrm{E}\right)$ near the west coast; $\operatorname{Bidar}\left(17 \cdot 55^{\circ} \mathrm{N}, 77 \cdot 32^{\circ} \mathrm{E}\right)$ in the northeastern part; and Devanahalli $\left(13 \cdot 15^{\circ} \mathrm{N}, 77 \cdot 42^{\circ} \mathrm{E}\right)$ in the southeastern part. 


\section{Measures of coherence}

The degree to which the variations in the rainfall at one station are related to that at another station can be estimated by the cross-correlation. When the cross-correlation of the annual rainfall is high, the anomalies in the annual rainfall i.e. drought or excess rains are likely to occur simultaneously over the two stations. Obviously, the correlation between any two stations in a coherent zone has to be statistically significant for the rainfall over the time-scales of interest such as seasonal, annual etc. Whether this condition is satisfied by the existing meteorological subdivisions can be easily tested. Tables 1-3 show the correlations of the different stations of the meteorological subdivisions of Karnataka relative to the one arbitrarily chosen station in each. It is seen that the correlations are not significant at $5 \%$ level for several stations. Thus the existing meteorological zones cannot be considered to be coherent even for variations of annual rainfall and it is necessary to determine anew the coherent zones of the State.

Table 1. Meteorological subdivision: South Karnataka (central station: Kolar).

\begin{tabular}{|c|c|c|c|c|c|}
\hline \multirow[b]{2}{*}{ Stations } & \multicolumn{4}{|c|}{ Correlations } & \multirow{2}{*}{$\begin{array}{c}\text { Mean } \\
\text { disparity } \\
\text { index }\end{array}$} \\
\hline & Annual & $\begin{array}{c}\text { Pre } \\
\text { monsoon }\end{array}$ & $\begin{array}{l}\text { Summer } \\
\text { monsoon }\end{array}$ & $\begin{array}{c}\text { Post } \\
\text { monsoon }\end{array}$ & \\
\hline Devanhalli & 0.74 & 0.41 & 0.69 & 0.75 & 0.20 \\
\hline Bangalore & 0.71 & 0.60 & 0.66 & 0.76 & $0 \cdot 19$ \\
\hline Chikaballapur & 0.63 & 0.39 & 0.55 & 0.69 & 0.21 \\
\hline Bagepalli & 0.61 & 0.40 & 0.51 & 0.59 & $0 \cdot 23$ \\
\hline Harihar & 0.57 & 0.48 & $0-48$ & 0.47 & $0-29$ \\
\hline Tumkur & 0.56 & $0 \cdot 31$ & $0 \cdot 50$ & 0.67 & 0.23 \\
\hline Kadur & 0.55 & $0 \cdot 30$ & 0.29 & 0.51 & 0.29 \\
\hline Challakere & 0.53 & $\underline{0.17}$ & 0.43 & $0 \cdot 40$ & 0.30 \\
\hline Chitradurga & 0.53 & $\overline{0.20}$ & $0 \cdot 38$ & 0.55 & $0 \cdot 26$ \\
\hline Kanakapura & 0.52 & 0.54 & 0.36 & 0.68 & $0 \cdot 22$ \\
\hline Arsikere & 0.52 & $0 \cdot 23$ & 0.36 & 0.63 & 0.25 \\
\hline Pavagada & 0.52 & $\underline{0.18}$ & 0.55 & 0.60 & 0.26 \\
\hline Hospet & 0.51 & $\overline{0.31}$ & 0.44 & 0.51 & 0.28 \\
\hline K. R. pet & 0.48 & 0.29 & 0.49 & 0.54 & 0.27 \\
\hline Hassan & 0.48 & 0.30 & 0.43 & 0.45 & 0.28 \\
\hline Kollegal & 0.47 & 0.35 & 0.52 & 0.56 & $0 \cdot 24$ \\
\hline Gundlupet & 0.46 & 0.22 & 0.59 & 0.53 & $0 \cdot 29$ \\
\hline Bellary & 0.45 & 0.27 & 0.50 & 0.42 & $0 \cdot 28$ \\
\hline Mysore & 0.41 & $0 \cdot 31$ & 0.32 & 0.56 & 0.25 \\
\hline Mandya & 0.40 & $0 \cdot 21$ & 0.61 & 0.51 & 0.25 \\
\hline Harpanahalli & 0.38 & 0.20 & $0 \cdot 38$ & $0 \cdot 40$ & 0.27 \\
\hline Chikmagalur & $0 \cdot 31$ & $0 \cdot 24$ & 0.25 & $0-38$ & $0 \cdot 30$ \\
\hline Shimoga & 0.17 & $0-28$ & $0 \cdot 10$ & 0.46 & $0 \cdot 36$ \\
\hline Somwarpet & $\overline{0.07}$ & $0 \cdot 16$ & $\overline{0.04}$ & 0.44 & 0.44 \\
\hline Sorab & 0.07 & $\overline{0 \cdot 27}$ & $\overline{0.08}$ & 0.35 & 0.46 \\
\hline Mercara & 0.05 & 0.26 & $\underline{0.00}$ & $0-54$ & 0.45 \\
\hline Virajpet & $\overline{0.02}$ & 0.22 & 0.07 & $0 \cdot 34$ & 0.43 \\
\hline
\end{tabular}

Correlations which are not significant at $5 \%$ level have been underlined. 
Table 2. Meteorological subdivision: North Karnataka (central station: Gulbarga).

\begin{tabular}{|c|c|c|c|c|c|}
\hline \multirow[b]{2}{*}{ Stations } & \multicolumn{4}{|c|}{ Correlations } & \multirow{2}{*}{$\begin{array}{c}\text { Mean } \\
\text { disparity } \\
\text { index }\end{array}$} \\
\hline & Annual & $\begin{array}{c}\text { Pre } \\
\text { monsoon }\end{array}$ & $\begin{array}{l}\text { Summer } \\
\text { monsoon }\end{array}$ & $\begin{array}{c}\text { Post } \\
\text { monsoon }\end{array}$ & \\
\hline Bidar & 0.49 & 0.53 & 0.49 & 0.57 & 0.21 \\
\hline Indj & 0.46 & 0.23 & 0.49 & 0.44 & $0 \cdot 26$ \\
\hline Raichur & 0.46 & 0.54 & 0.49 & $0-42$ & $0 \cdot 23$ \\
\hline Bijapur & 0.42 & $0 \cdot 63$ & 0.49 & $0-50$ & 0.26 \\
\hline Chikodi & 0.41 & $0 \cdot 21$ & 0.42 & $0-44$ & 0.32 \\
\hline Muddebihal & 0.41 & $0 \cdot 32$ & 0.54 & 0.43 & 0.27 \\
\hline Bagalkot & $0 \cdot 35$ & 0.31 & $0 \cdot 37$ & 0.48 & 0.29 \\
\hline Gokak & 0.34 & 0.27 & 0.44 & 0.43 & $0 \cdot 32$ \\
\hline Ron & 0.33 & 0.27 & $0 \cdot 36$ & 0.45 & $0 \cdot 29$ \\
\hline Athni & 0.26 & 0.31 & 0.36 & 0.39 & 0.30 \\
\hline Mudhol & 0.22 & 0.22 & $0 \cdot 32$ & 0.43 & 0.29 \\
\hline Ranebennur & 0.14 & $0 \cdot 25$ & 0.05 & $0 \cdot 30$ & $0 \cdot 34$ \\
\hline Hangal & $\overline{0 \cdot 12}$ & $0 \cdot 24$ & $\overline{0.02}$ & $0 \cdot 36$ & $0 \cdot 35$ \\
\hline Dharwar & $\overline{0.09}$ & 0.26 & $\overline{0 \cdot 10}$ & 0.44 & $0 \cdot 31$ \\
\hline Belgaum & $\overline{0.08}$ & 0.05 & $\overline{0 \cdot 11}$ & 0.28 & 0.37 \\
\hline
\end{tabular}

Correlations which are not significant at $5 \%$ level have been underlined.

Table 3. Meteorological subdivision: West Coast (central station: Sirsi).

\begin{tabular}{lccccc}
\hline & \multicolumn{4}{c}{ Correlations } & Mean \\
\cline { 2 - 4 } Stations & Annual & $\begin{array}{c}\text { Pre } \\
\text { monsoon }\end{array}$ & $\begin{array}{c}\text { Summer } \\
\text { monsoon }\end{array}$ & $\begin{array}{c}\text { Post } \\
\text { monsoon }\end{array}$ & $\begin{array}{c}\text { disparity } \\
\text { index }\end{array}$ \\
\hline Supa & 0.73 & 0.68 & 0.75 & 0.67 & 0.10 \\
Beltangady & 0.64 & 0.73 & 0.66 & 0.52 & 0.13 \\
Karwar & 0.53 & 0.73 & 0.54 & 0.50 & 0.20 \\
Mangalore & 0.40 & 0.72 & 0.40 & 0.37 & 0.20 \\
Coondapur & 0.35 & 0.65 & 0.41 & 0.40 & 0.18 \\
\hline
\end{tabular}

We use the cross-correlation of annual rainfall as an important measure of the coherence of the variations of rainfall at a pair of stations. The starting point of our analysis is, therefore, the correlation matrix of the annual rainfall for the 50 raingauge stations computed by utilizing the 85 -year data set. Since our aim is to identify zones which are coherent not only with respect to annual rainfall but with respect to seasonal rainfall as well, in addition to the cross-correlation for annual rainfall we also have to take into account the coherence of the monthly rainfall pattern. For this, another measure of similarity (or rather disparity) of monthly patterns of the rainfall is used. The rainfall pattern at a given station during a specific year can be represented as a point in the twelve-dimensional space of monthly rainfall. We define the Euclidean distance between the points representing the rainfall patterns at the stations of interest as the disparity index between the stations for the specific year chosen. Since the 


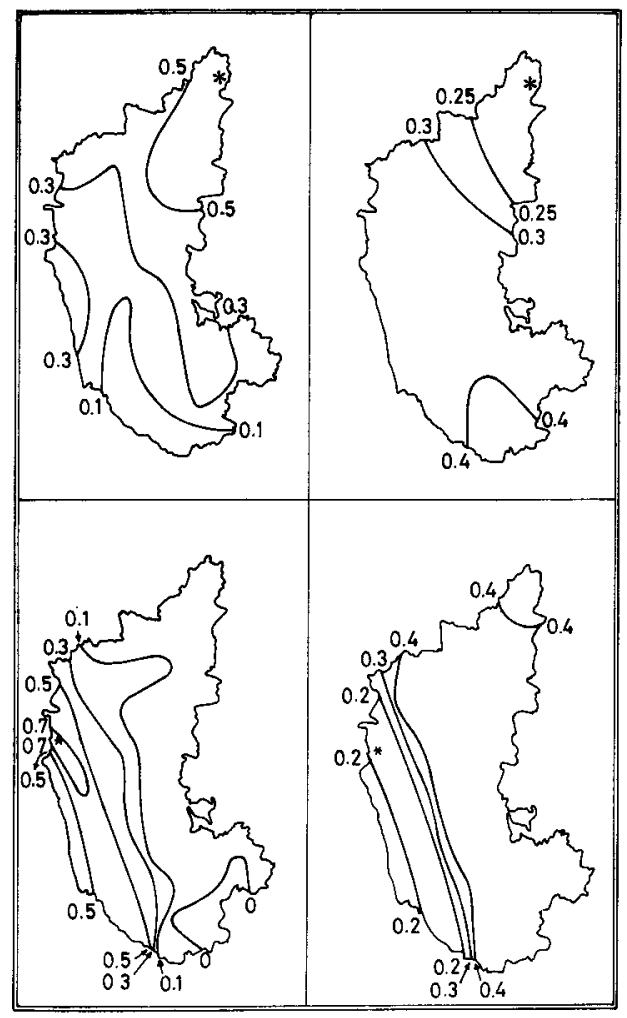

Figure 4. Correlation of annual rainfall and mean disparity index with respect to two representative stations viz Supa and Bidar.

coherence of the total quantum of rainfall received duing the year is assessed by the cross-correlation of annual rainfall, we use normalized rainfall pattern (i.e. the fraction of rainfall received in each month) in computing the disparity index. Various measures of the disparity between the patterns at a given pair of stations, such as the mean, mode etc. can be calculated from the 85-year data set. The cross-correlation of annual rainfall and the mean value of the disparity index are used as measures of coherence and of lack of coherence respectively in our method for delineating the coherent zones. However the same results are obtained if the mode of the 85-year distribution of the disparity index is used instead of the mean.

The spatial variation of the correlation of the annual rainfall and the mean disparity index relative to two representative stations viz. Bidar in the northeastern parts and Supa near the west coast are shown in figure 4 . It is seen that the coherence relative to Supa decreases rapidly in the eastward direction (figures $4 c, d$ ) across the Western Ghats and becomes statistically insignificant over the interior parts of the State. The region with maximum coherence relative to this station is a zone parallel to the west coast. Thus it is clear that the coastal belt cannot be clubbed with the interior parts of the State to form a coherent zone. The variation of the cross-correlation relative to 
Bidar in the northeastern region (figures $4 a, b$ ) indicates that the interior itself is not a coherent zone since the annual rainfall over the southern part of interior Karnataka is poorly correlated with that over the northeastern part. Thus it is clear that at least three zones are necessary; whether three zones are adequate will be determined in this study. Even in the event of three zones being adequate, they have to be delineated anew since the existing meteorological subdivisions of interior Karnataka are not coherent. We consider next the methodology for delineation of coherent zones.

\section{Delineation of coherent zones}

\subsection{The approach}

The number of coherent zones depends on the degree of coherence demanded within each zone. The minimum requirement is that the cross-correlation for the rainfall over the time scale of interest between any pair of stations within a coherent zone be statistically significant. We seek to delineate coherent zones which satisfy the condition that the correlation of the annual rainfall as well as the rainfall in the two major rainy seasons of summer monsoon and post-monsoon, between any two stations within a zone is significant at $5 \%$ level (i.e. $\geqslant 0.21$ for a sample of 85 years assuming a Gaussian distribution). We are interested in determining the minimum number of coherent zones in which the State can be divided, such that the minimum requirement of coherence is satisfied for each zone. It is clear from figure 4 that the State as a whole cannot be considered as a coherent zone because stations within the State are poorly correlated even on the annual scale. The upper limit on the number of coherent zones is obviously provided by the trivial case of each station being considered as an independent zone when maximum coherence is achieved within each zone.

The problem of delineation of coherent zones is somewhat complex because all measures of coherence such as the cross-correlation refer to relationship between variations at a pair of stations. Thus the problem is akin to the analysis of the distribution of points when the co-ordinates are not known but the matrix of interpoint distance is known. In this situation, it is not easy to analyse the distribution of the points to identify the clusters or groups of coherent stations. However, relative to a given central station, the stations at which the variations are sufficiently coherent (i.e. with values of correlation coefficients above and disparity index below specified thresholds) can be readily identified. Thus if a network of central stations which represent the entire gamut of the observed variation can be identified objectively, coherent zones can be delineated by assigning stations appropriately to the different central stations or seed points. This is the approach we have adopted in this study.

In order to determine the minimum number of zones into which the State can be divided, we begin by investigating the possibility of having only two zones. As expected from the discussion at the end of the last section, we find that these zones cover only a part of the State, the rest of the State comprising a large number of stations which cannot be assigned to either of these zones without violating the imposed condition on the minimum correlation within a zone. As the number of zones is increased, the number of stations which cannot be assigned to any zone decreases until the final stage at which the entire State is covered. We consider next the methodology for choosing the central stations or seed points and assignment of stations to these. 


\subsection{Choice of centres}

The obvious choice for the first two central stations/seed points is the pair of stations with the lowest value of correlation of annual rainfall. For the stations analysed here this minimum correlation turns out to be negative i.e. -0.15 between Supa near the west coast and Devanahalli in the southeastern part. It is clear that these two stations cannot be assigned to the same zone. The next seed point is chosen as that station which is most poorly correlated with each of the seed points chosen earlier. This would be analogous to seeking the point which is farthest from the chosen seed points in the analysis of the spatial distribution of points. Specifically, the station with the minimum value of the maximum correlation relative to the seed points already chosen is selected as the next seed point. The process of selection of the seed points can be illustrated by describing the identification of the third seed point after the first two have been chosen as those with a minimum value of the cross-correlation viz. Supa and Devanahalli. Let the correlation of a station $i$ of the remaining 48 stations, with Supa and Devanahalli be $r_{\mathrm{S}_{i}}$ and $r_{\mathrm{D}_{i}}$ respectively. We consider only the maximum correlation relative to the already chosen seed points, $R_{i}$ which is given by

$$
R_{i}=\text { Maximum of } r_{\mathrm{S}_{i}} \text { and } r_{\mathrm{D}_{i}} \text {. }
$$

The value of $R_{i}$ will be large for any station $i$ which is well correlated with either of the chosen seed points i.e. Supa or Bidar. A small value of $R_{i}$ indicates that the station $i$ is poorly correlated with both the seed points. The minimum value of this maximum correlation will occur for a station which is least correlated with the set of seed points chosen. This station is chosen as the next seed point. This process is continued until an adequate network of central stations representing the entire gamut of variation in the study region is obtained.

\subsection{Formation of coherent zones}

Once the seed points/central stations are identified, the assignment of stations to the given set of central stations to form coherent zones/groups of stations is done as follows. At the first instance, the station which is best correlated with the central station considered, is assigned to it provided that (i) its mean disparity index relative to that central station is less than that relative to the other central stations and (ii) the minimum correlation of annual rainfall within the region so formed exceeds a specified threshold viz 0.3 . The threshold in the second condition has been chosen to be somewhat stringent, implying correlations significant at $1 \%$ level, so as to ensure coherence on seasonal and monthly scales. Once the group membership increases to two or more, it is necessary to ensure that any new station added is better correlated with the set of stations included in that group than it is to the set of stations in the other groups. Hence we consider the correlation of each unassigned station with every member of the group. If a group consists of stations $1,2, \ldots, n$, from the correlations of the unassigned station $i$ with each member viz $r_{i k}$ for $k=1,2, \ldots, n$ we take the

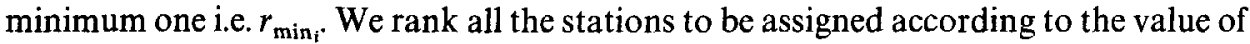
$r_{\min _{i}}$ in descending order. Thus the station with the first rank is characterized by the largest value of the minimum correlation relative to the stations already assigned to the group. Since this station is better correlated with the group as a whole than any other 
station, it is assigned to that zone provided that conditions (i) and (ii) above are satisfied.

At the first instance, when only two central stations are used, we find that several stations cannot be assigned to either of the two coherent zones without violating one of these conditions. As the number of central stations increases, more and more parts of the State get represented and the number of such unassignable points decreases, until eventually the entire study region is covered. At each stage, the coherence of the seasonal rainfall within the identified zones is also assessed. The final results are the same if a threshold of 0.2 is used in condition (ii); differences arise only in the intermediate stages. The detailed delineation of the coherent zones of Karnataka using the methodology described here is discussed in the next section.

\section{Coherent zones of Karnataka}

As seen from figure 4 the annual rainfall at stations near the west coast is rather poorly correlated with that over the southeastern part of the State. In fact, the pair of stations with the poorest correlation comprises one station from each of these regions. We consider first the division of the State into two coherent zones using these stations as the central stations or seed points. We find that using the methodology described in the previous section, only 27 of the 50 stations can be assigned to the coherent zones formed (figure 5.I). The remaining 23 stations cannot be assigned to either of the two coherent zones without violating the imposed condition on the minimum correlation between any two stations within a coherent zone. Since the coherent zones cover only a part of the State with a large number of stations in the northern part of the State remaining unassigned, we may conclude that two zones are not adequate. We next consider the possibility of dividing the State into three coherent zones.

Not surprisingly, the third central station appears in the northeastern part of the State (figure 5.II). At this stage the number of unassigned stations is reduced to 17. Of these the majority cannot be assigned without violating the imposed condition of the minimum correlation within a zone. The remaining four stations occur near the boundaries of the zones and cannot be assigned to any of the three zones because the condition that the disparity index must be minimum relative to the central station of the zone to which the station is assigned cannot be satisfied in their case. In other words although each of these stations is better correlated on the annual scale with the stations of one zone, it is closer to another zone on the seasonal and monthly scale. It is seen that even with three coherent zones fairly large regions in the northwestern and southern parts of the State remain unassigned. Hence it is clear that more than three zones are required.

To determine the minimum number of zones into which the State can be divided, we continue this exercise of adding one centre at a time, delineating the corresponding 

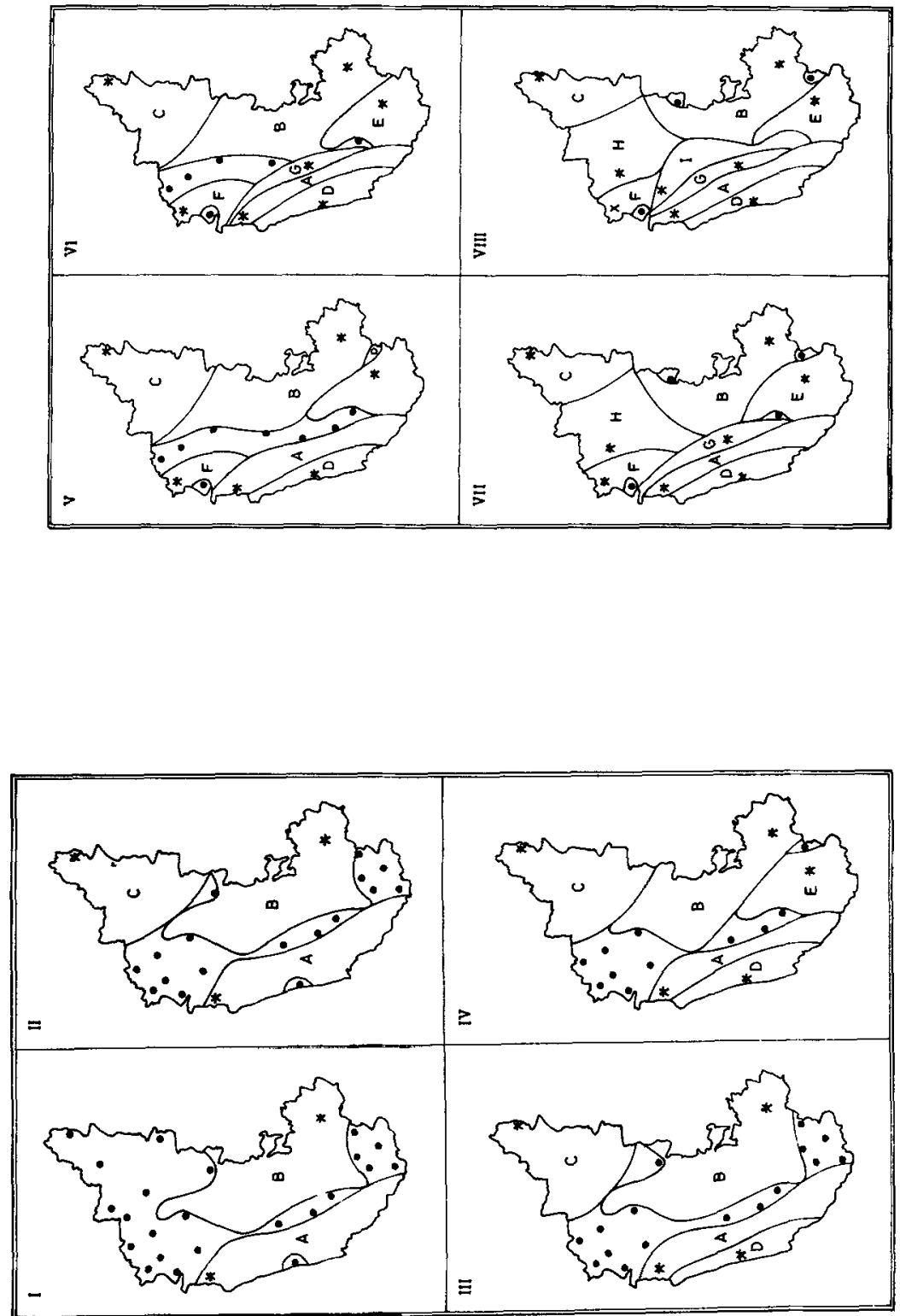


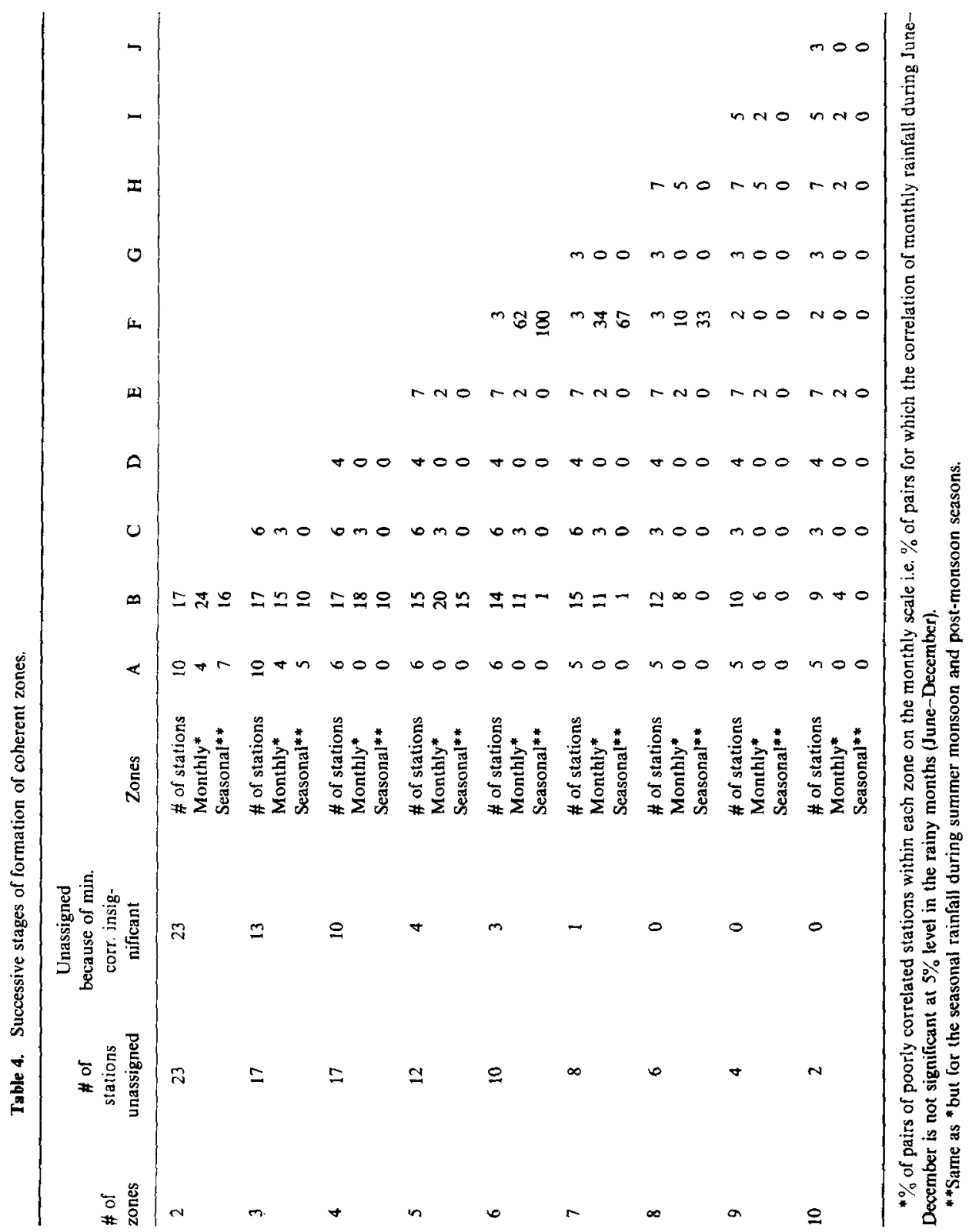


coherent zones, checking the extent of the State covered by these coherent zones, and the coherence within each such zone on seasonal and monthly scales. Detailed results are given in table 4 in which information about the number of unassigned stations at each stage as well as the reason for their unassignability is also included.

It can be seen that in zones $A$ and $B$ formed at the first stage, the correlation on the seasonal and monthly scales is not significant for a few pairs of stations; the number of such pairs being somewhat larger for the sprawling zone $B$ than the coastal zone $A$. Zone $C$ added at the next stage is more coherent on seasonal and monthly scales. At this point, another central station appears on the west coast, resulting in a splitting of $A$ into two zones which are completely coherent on monthly and seasonal scales. As more centres appear, more zones are formed, the membership of the earlier zones changes and the number of pairs of stations which are not significantly correlated on seasonal and monthly scales reduces. At the final stage (figure 6) the zones are coherent on the seasonal scale and largely so even on the monthly scale.

So far we have considered a zone to be coherent on the timescale of interest if the correlation between any two stations in the zone is significant at $5 \%$. The next task is to determine whether this condition is adequate to ensure that large anomalies of opposite signs do not occur simultaneously over such a zone so that the delineated zones fulfil the original purpose of providing meaningful averages. To ascertain this, it is first necessary to define what constitutes large anomalies. In the case of negative anomalies, this amounts to defining droughts in terms of the deficit in rainfall. We consider this problem next.

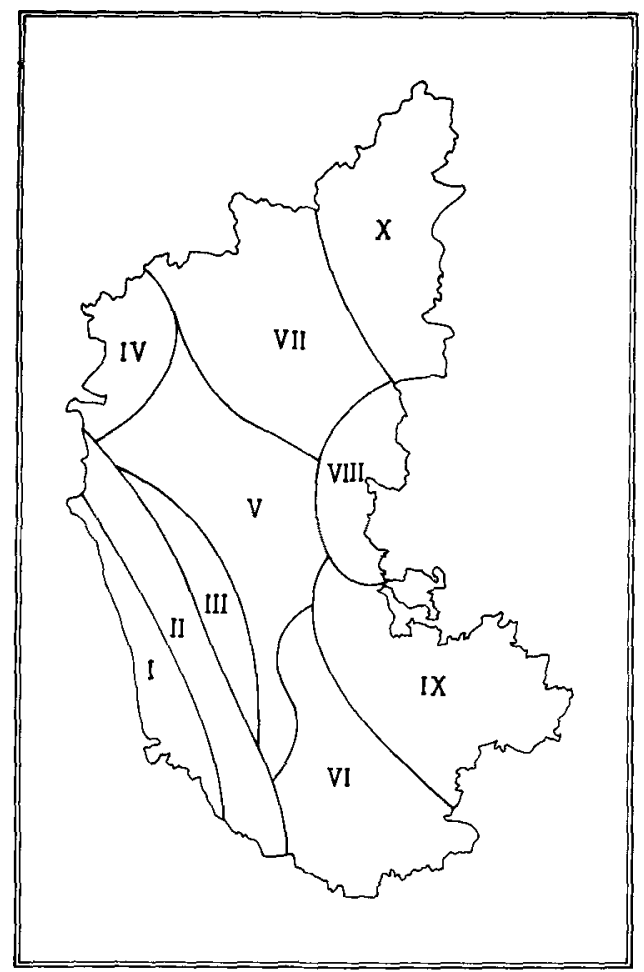

Figure 6. Coherent zones of Karnataka. 


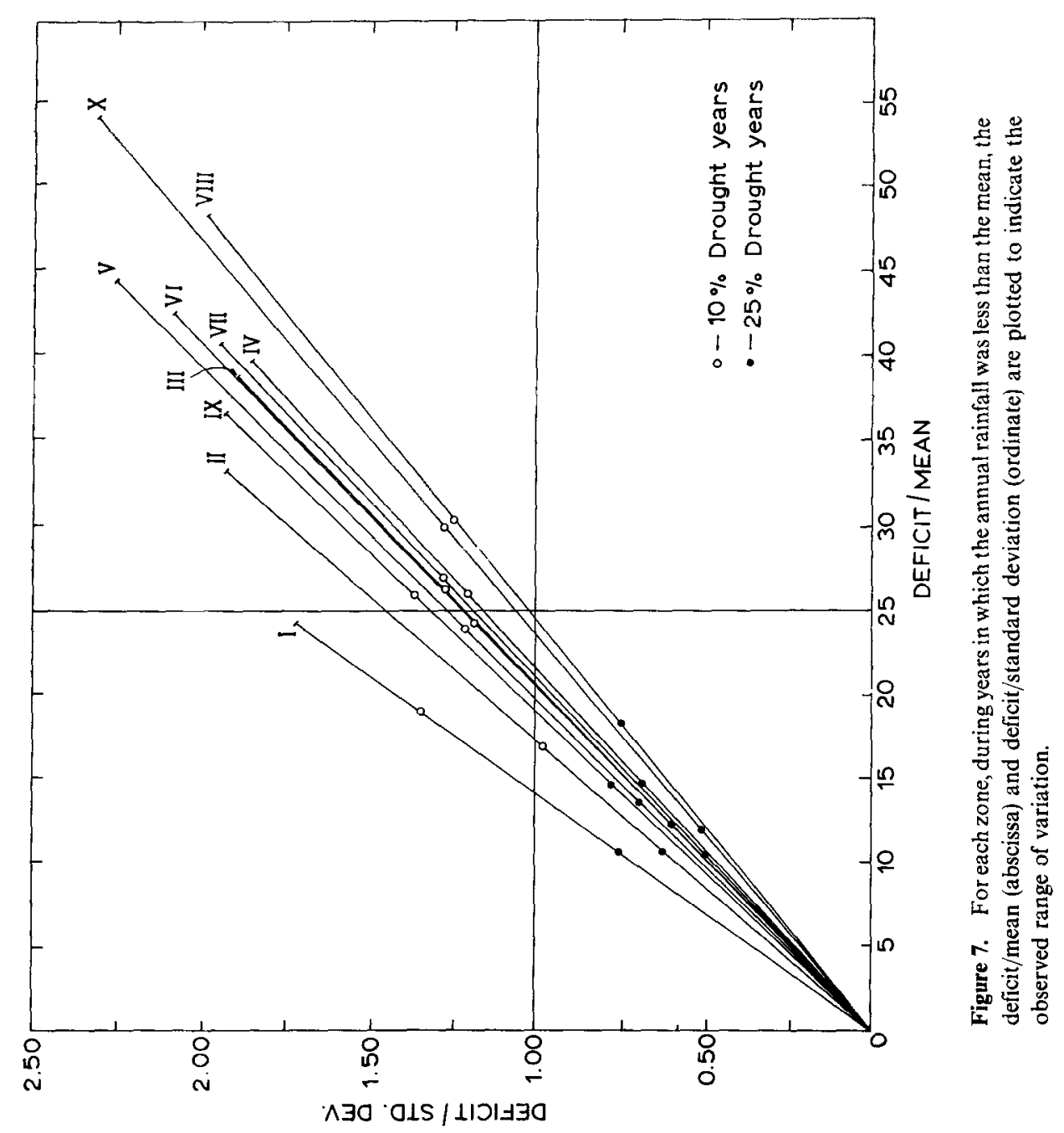




\section{Droughts and coherent zones}

There is no universally accepted definition of droughts. Obviously meteorological droughts are associated with deficit rainfall. But how large does this deficit have to be for the year/season to be declared as a drought? Logically this should be determined by the nature of the impact of the deficit on the critical resources of the region. If the resource utilization strategy is rational, the impact will not be large unless the rainfall deficit exceeds the expected variation of the rainfall over the region. Hence in one approach to the definition of drought, the deficit is scaled by the simplest measure of variability viz the standard deviation and drought is said to occur when the deficit exceeds the standard deviation or some multiple thereof (e.g. Shukla 1986). The multiplicative factor is often taken to be 1.28 because when the distribution is normal, the probability of the deficit exceeding 1.28 times the standard deviation is $10 \%$. A generalization of this definition to omit the dependence on the nature of the distribution is to define drought as a $10 \%$ probability event from the observed distribution of the time variation for the region of interest. In the second approach to the definition of droughts, the yardstick used for assessing the deficit of rainfall is the mean rainfall over the region. Thus according to IMD (1971) drought is said to occur when the rainfall is less than $75 \%$ of the mean i.e. the deficit exceeds $25 \%$ of the mean rainfall.

The implications of all these definitions of drought for the different zones of figure 6 are shown in figure 7 in which the range of the variation of the deficits in the zonal average annual rainfall during 1901-85 scaled by the mean rainfall (abscissa) and by the standard deviation (ordinate) is shown. The range of the deficits in the $10 \%$ and $25 \%$ years with lowest rainfall is also indicated therein. It is seen that if the IMD (1971) definition of drought is used, not a single drought occurred during 1901-85 in the coastal zone I, while only three occurred in the adjacent zone II. On the other hand, the frequency of droughts thus defined in zones VII and IX is larger than $10 \%$. For the ramaining zones the IMD criterion implies droughts in about $10 \%$ of the years.

If droughts are defined as years with deficits larger than one standard deviation, the frequency in zone II is about $10 \%$ whereas it is much larger in all the other zones including the coastal zone. If a factor of 1.28 is used in the definition of droughts, the frequency is close to $10 \%$ for all the zones with the exception of zone II in which it is about $5 \%$. Thus if the definition of droughts is to be based primarily on the observed variation of rainfall, it may be best to define it as an event of a given probability e.g. as a chance of 1 in 10 event. Such droughts for the two major rainy seasons in the different zones are shown in figure 8 . The minimum value of the deficit characterizing a drought has then to be derived from the observed variation over the region. The same concept can be used in defining the categories of the above normal and the below normal rainfall.

The extent to which the objective of this study viz identification of zones which are sufficiently coherent for identification of droughts or conditions of above or below normal rainfall has been achieved can be assessed once we define precisely what constitutes a drought or a situation with above/below normal rainfall.

Consider first a case in which we take $25 \%$ of the years with lowest/highest rainfall to represent the below/above normal rainfall at a particular station. The frequency of simultaneous occurrence of stations with above and below normal rainfall within a zone/region can be taken as a measure of the lack of coherence in that zone/region. We find that for the meteorological subdivisions of interior Karnataka a majority of the 


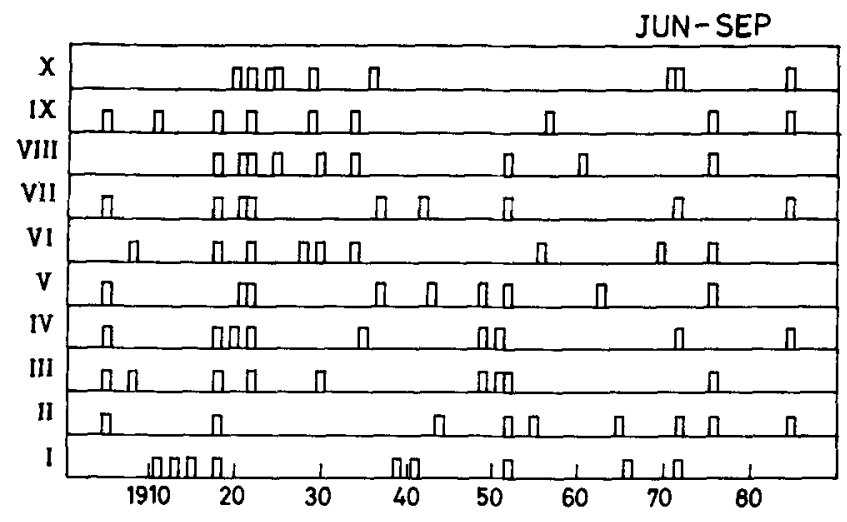

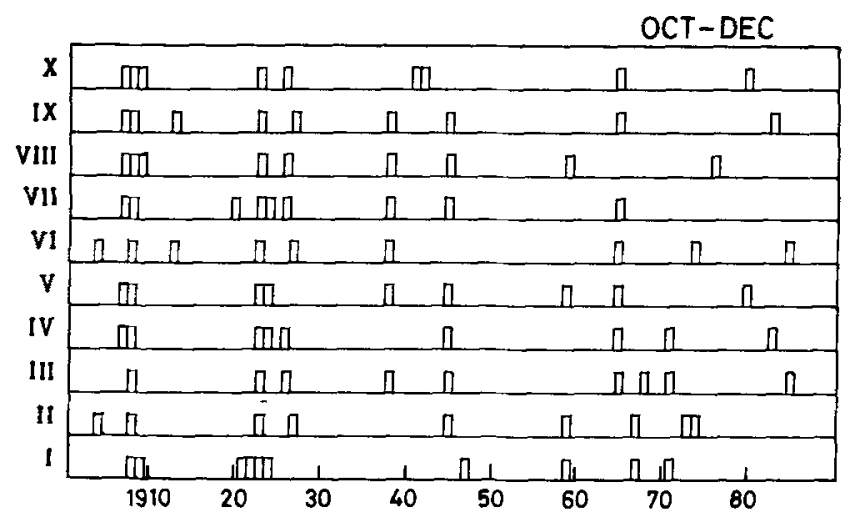

Figure 8. Droughts in the different zones during the two major seasons when drought is defined as a chance of 1 in 10 events.

years ( $74 \%$ for the southern and $54 \%$ for the northern subdivision) were characterized by such simultaneous occurrence of above and below normal rainfall. On the other hand, for the rainfall zones determined here, in a vast majority of years (ranging from $71 \%$ to $94 \%$ for the different zones), the rainfall variations are completely coherent with anomalies of the same sign within each zone i.e. all the stations within a zone experiencing below normal/normal in some years and above normal/normal rainfall in others. Another index of the lack of coherence within a zone for a particular year is the product of the fraction of stations simultaneously experiencing above and below rainfall; this product is zero for years when the zone is completely coherent. The mean value of this product over the 85 years ranged from $0.3 \%$ to $1.5 \%$ for these zones. Thus the zonal average appears to be a meaningful estimate of the rainfall at the different stations within a zone. We find that for most of the zones when the zonal average rainfall is below normal, the rainfall is not above normal at any of the individual stations comprising the zone. The exceptions are the zones V, VII and IX in which during $2-4 \%$ of the station-years, rainfall slightly above normal was recorded when the zonal average was below normal. If we define drought as a $10 \%$ probability event and consider the drought years for each zone when the zonal average rainfall is in the lowest $10 \%$ category, we find that at no station is the rainfall above normal in any zone. $\mathrm{A}$ 
majority of the stations (ranging from $70 \%$ to $82 \%$ for the different zones) experience drought during these years. Thus we may conclude that the zones delineated here are sufficiently coherent for estimating the performance of the monsoon and identifying droughts on the seasonal/annual scale.

\section{Acknowledgements}

It is a pleasure to thank Prof. R Narasimha and Dr N V Joshi for many stimulating discussions and Prof. $R$ Ananthakrishnan for detailed comments. This research was supported by a grant from ISRO.

\section{References}

IMD 1971 Rainfall and drought in India. India Meteorological Department Publication, pp. 22-23

Rao Y P 1976 Southwest monsoon. Meteorological Monographs, Synoptic Meteorology 1/1976, India Meteorological Department, New Delhi, pp. 367

Shukla J 1986 Interannual variability of monsoon; in Monsoons (eds) J S Fein and P L Stephens (New York: Wiley-Interscience) 